\title{
Oral contraceptive failures and body weight: Findings in a large cohort study
}

\author{
Martin Vessey, CBE, MD, FRCOG, FRS, Emeritus Professor of Public Health; Rosemary Painter, D.Phil, Computer Scientist, \\ Institute of Health Sciences, Oxford, UK.
}

Correspondence: Martin Vessey, Unit of Health Care Epidemiology, University Department of Public Health, Institute of Health Sciences, Headington, Oxford, OX3 7LF, UK.

(Accepted November $\left.6^{\text {th }}, 2000\right)$

\begin{abstract}
Summary
This report looks at data from 17032 women who took part in the Oxford Family Planning Association contraceptive study. Thirty-eight first accidental pregnancies occurred during 6779 woman-years of use of progestogen-only oral contraceptives (0.56 per 100) and 95 first accidental pregnancies occurred during 48692 woman-years of combined oral contraceptive use (0.20 per 100). Although associations with age and parity were found, there was no evidence of any influence of body weight on the risk of accidental pregnancy with either form of oral contraceptive.
\end{abstract}

\section{Key words}

accidental pregnancy, body weight, cohort study, oestrogens, oral contraception, progestogens

\section{Key message points}

- Accidental pregnancy rates in the Oxford-FPA study for women taking combined oral contraceptives (based on 95 pregnancies) and for women taking progestogen-only oral contraceptives (based on 38 pregnancies) were strongly negatively correlated with age and strongly positively correlated with parity.

- No associations were found with social class, smoking habits or duration of oral contraceptive use after adjustments had been made for the effects of age.

- Both age adjusted and age and parity adjusted failure rates for the two types of oral contraceptive were not significantly related to body weight, height or body mass index.

\section{Introduction}

In 1990, in response to an enquiry, we published findings from the Oxford-Family Planning Association (OxfordFPA) contraceptive study about the effectiveness of progestogen-only oral contraceptives (POPs) in relation to the body weight of the user. ${ }^{1}$ We had information on only 35 accidental pregnancies, occurring during 4407 womanyears of use. The highest failure rate was found among the heaviest women, but the numbers were too small for any conclusions to be drawn.

In early 2000 we received a similar enquiry, but on this occasion we were asked about the possible relationship between oral contraceptive failure and body weight for combined preparations (COCs) as well as for POPs. We were also asked to examine the data for women weighing $82 \mathrm{~kg}(180 \mathrm{lb})$ or more as a special category. We thought that the findings might be of general interest, and we present a summary of the results here.

\section{Method}

The methods used in the Oxford-FPA study have been reported in detail elsewhere. ${ }^{2}$ Briefly, 17032 white married women, aged 25-39 years, using oral contraceptives (OCs), a diaphragm or an intra-uterine device were recruited at 17 family planning clinics in England and Scotland between 1968 and 1974. Information about a range of medico-social variables was collected from each woman at admission to the study. Data collected during follow-up, which ended in 1994, included details of changes in contraceptive practices and reasons for the changes. It is thus possible to identify accidental pregnancies occurring with each contraceptive method and to relate them to the corresponding period of exposure. The present analysis is concerned with useeffectiveness, that is both method failures and user failures are included.

Losses to follow-up in the Oxford-FPA study for reasons which might bias the results were kept to a very low level, amounting to only about four women per 1000 per year.

\section{Results}

Thirty-eight first accidental pregnancies occurred during 6779 woman-years of POP use (0.56 per $100,95 \%$ confidence interval [CI] 0.40-0.78). The corresponding figures for COCs were 95 first accidental pregnancies during 48692 woman-years of use $(0.20$ per $100,95 \%$ CI 0.16-0.24).

Before examining the relationship between the risk of accidental pregnancy and body weight, we investigated the effects of age, parity, social class, cigarette smoking and duration of OC use as potential confounding variables. The failure rates for POPs showed a strong inverse association with age, falling from 3.36 (95\% CI 0.92-8.61) per 100 woman-years at ages $25-29$ to 0.28 (95\% CI $0.11-0.58)$ per 100 woman-years at ages 40-44. There was a similar but weaker association for $\mathrm{COCs}$, the corresponding rates being 0.24 (95\% CI $0.16-3.51)$ and 0.07 (95\% CI 0.02-0.17), respectively.

There was also an association between failure rates and parity. For POPs the age adjusted rate rose from $0.10(95 \%$ CI 0.00-0.54) per 100 woman-years for nulliparous women to 1.83 (95\% CI $0.67-3.99)$ per 100 woman-years for women who had had four or more children. The corresponding rates for COCs were 0.06 (95\% CI 0.02 0.14 ) and 0.44 (95\% CI 0.23-0.75), respectively.

The age adjusted failure rates for both types of OC showed no significant relationships with social class, cigarette smoking or duration of pill use. Accordingly, we proceeded to examine the failure rates for the two types of OC, adjusted first for age alone and then for age and parity, in relation to body weight. Neither analysis provided any indication of an association; the results for the second set of analyses are given in Table 1 . We also examined the failure rates by height and by body mass index, with similar negative results. Finally, as requested, we contrasted the overall failure rates for women weighing less than $82 \mathrm{~kg}$ $(180 \mathrm{lb})$ with those for women weighing $82 \mathrm{~kg}(180 \mathrm{lb})$ or more. In the former group, the overall rate (adjusted for age and parity) was 0.24 (95\% CI $0.20-0.28)$ per 100 womanyears and in the latter group (similarly adjusted) it was 0.38 
Table 1 Numbers of accidental pregnancies, failure rates per 100 woman-years and 95\% confidence intervals for progestogen-only and combined oral contraceptives by body weight of the user. The rates are adjusted for age and parity.

\begin{tabular}{|c|c|c|c|c|c|c|}
\hline $\begin{array}{c}\text { Body weight } \\
\mathrm{Kg}(\mathrm{lb})\end{array}$ & \multicolumn{2}{|c|}{ Progestogen-only } & \multicolumn{2}{|r|}{ Combined } & \multicolumn{2}{|r|}{ Total } \\
\hline$-51(-112)$ & 4 & $0.43(0.12-1.10)$ & 18 & $0.24(0.14-0.38)$ & 22 & $0.26(0.16-0.40)$ \\
\hline $51-57(113-126)$ & 14 & $0.61(0.33-1.02)$ & 32 & $0.21(0.15-0.30)$ & 46 & $0.27(0.19-0.35)$ \\
\hline $58-64(127-140)$ & 12 & $0.60(0.31-1.05)$ & 29 & $0.20(0.13-0.28)$ & 41 & $0.25(0.18-0.33)$ \\
\hline $64-70(141-154)$ & 3 & $0.29(0.06-0.86)$ & 11 & $0.15(0.08-0.27)$ & 14 & $0.17(0.09-0.28)$ \\
\hline $70-76(155-168)$ & 4 & $1.49(0.41-3.83)$ & 2 & $0.08(0.01-0.28)$ & 6 & $0.21(0.08-0.45)$ \\
\hline 77- (169-) & 1 & $0.52(0.01-2.91)$ & 3 & $0.21(0.04-0.61)$ & 4 & $0.25(0.07-0.64)$ \\
\hline $\mathrm{p}$ value for trend & & 0.63 & & 0.14 & & 0.27 \\
\hline
\end{tabular}

Groups used in adjustment:- Age (years) 5 year groups from 25-29

Parity (no. births) $0,1,2,3,4-$.

(95\% CI 0.08-1.12) per 100 woman years. Of the three accidental pregnancies in the latter group, one occurred in a POP user and two in COC users.

\section{Discussion}

The present analysis was undertaken in response to a request for an update of our earlier report ${ }^{1}$ and its extension to include COCs. Although strong effects of age and parity were found, there was no evidence of any influence of body weight on the risk of accidental pregnancy. In the comparison between those weighing less than $82 \mathrm{~kg}(180 \mathrm{lb})$ and those weighing $82 \mathrm{~kg}(180 \mathrm{lb})$ or more, the rate was higher in the latter group, but it was based on only three accidental pregnancies and the difference did not approach statistical significance.

A careful Medline search identified no information about the risk of accidental pregnancy in relation to body weight in women using COCs. With regard to POPs, Sparrow ${ }^{3}$ reported on the weight of 94 women who became pregnant while using such pills. The absence of a control group made interpretation of the data difficult, but Sparrow concluded that there was no excess of failures in women who were overweight. Apart from an anecdotal report by Graham and Fraser $^{4}$ about a trial of POPs in which accidental pregnancies occurred only in heavier women, we were unable to find other directly relevant published information. There is, however, evidence that failure rates are related to body weight in women using Norplant ${ }^{\circledR}$ or levonorgestrel releasing vaginal rings. With regard to the former, Sivin ${ }^{5}$ reported that the gross cumulative accidental pregnancy rate at 5 years of Norplant ${ }^{\circledR}$ use was 0.2 per 100 women for those weighing less than $50 \mathrm{~kg}(110 \mathrm{lb})$; for those weighing $70 \mathrm{~kg}(154 \mathrm{lb})$ or more the corresponding rate was 7.6. With regard to the latter, the 1 year accidental pregnancy rate in a WHO vaginal ring study ${ }^{6}$ was found to be 1.8 per 100 women in those weighing up to $49 \mathrm{~kg}(108 \mathrm{lb})$ and 8.2 per 100 women in those weighing $70 \mathrm{~kg}(154 \mathrm{lb})$ or more.

\section{Conclusion}

In conclusion, the Oxford-FPA study offers no support to the hypothesis that the risk of accidental pregnancy is related to body weight in women using COCs. The same is true of those using POPs. Nonetheless, the findings in users of Norplant ${ }^{\circledR}$ and of levonorgestrel releasing vaginal rings raise the possibility that such a relationship does exist, but that the available data are too few to detect it.

\section{Acknowledgements}

We would like to thank Mrs J. Winfield, our research assistants and the staff at the participating clinics for their contributions to this project.

Statements on funding and competing interests.

Funding. The Oxford-FPA study is funded by a grant from the Medical Research Council.

Competing interests. None declared.

References

Vessey MP, Villard-Mackintosh L, Yeates D. Effectiveness of progestogen only oral contraceptives. Br J Family Planning 1990; 16: 79.

Vessey MP, Doll R, Peto R, et al. A long-term follow-up study of women using differen methods of contraception. Journal of Biosocial Science 1976; 8: 3373-3427.

Sparrow MJ. Pill method failures in women seeking abortion: fourteen years experience. $N Z$ Med J 1998; 111: 386-388.

Graham S, Fraser IS. The progestogen-only mini-pill. Contraception 1982; 26: 373-387. Sivin I. International experience with Norplant and Norplant-2 contraception. Stud Fam Plann

1988; 19: $881-894$.
World Health Organisation. Microdose intravaginal levonorgestrel contraception: a multicentre clinical trial. III. The relationship between pregnancy rate and body weight. Contraception 1990; 41: 1143-1150. 